\title{
Article \\ A Band-Switchable and Tunable THz Metamaterial Based on an Etched Vanadium Dioxide Thin Film
}

\author{
Jun-Hwan Shin ${ }^{1}$, Kyung Hyun Park ${ }^{2}$ and Han-Cheol Ryu ${ }^{3, *(1)}$ \\ 1 Terahertz Basic Research Section, Electronics and Telecommunications Research Institute (ETRI), \\ Daejeon 34129, Korea; jh.shin@etri.re.kr \\ 2 Future \& Basic Technology Research Division, Electronics and Telecommunications Research Institute (ETRI), \\ Daejeon 34129, Korea; khp@etri.re.kr \\ 3 Department of IT Convergence Engineering, Sahmyook University, Seoul 01795, Korea \\ * Correspondence: horyu@syu.ac.kr
}

Citation: Shin, J.-H.; Park, K.H.; Ryu, H.-C. A Band-Switchable and Tunable THz Metamaterial Based on an Etched Vanadium Dioxide Thin Film. Photonics 2022, 9, 89. https:// doi.org/10.3390/photonics9020089

Received: 13 January 2022

Accepted: 31 January 2022

Published: 2 February 2022

Publisher's Note: MDPI stays neutral with regard to jurisdictional claims in published maps and institutional affiliations.

Copyright: (c) 2022 by the authors. Licensee MDPI, Basel, Switzerland. This article is an open access article distributed under the terms and conditions of the Creative Commons Attribution (CC BY) license (https:// creativecommons.org/licenses/by/ $4.0 /)$.

\begin{abstract}
A band-switchable and tunable terahertz ( $\mathrm{THz}$ ) metamaterial based on a vanadium dioxide $\left(\mathrm{VO}_{2}\right)$ thin film was proposed in the $\mathrm{THz}$ frequency regime. The $\mathrm{VO}_{2}$ thin film with a high conductivity change rate and smooth phase transition characteristics was deposited. To obtain band switching characteristics and reduce $\mathrm{THz}$ wave loss, the $\mathrm{VO}_{2}$ thin film was etched in the form of a line. Two rectangular C-shaped resonators were configured to face each other, with an etched $\mathrm{VO}_{2}$ thin film line in between. When the $\mathrm{VO}_{2}$ thin film was in the insulator phase, the two resonators individually resonated, and when the $\mathrm{VO}_{2}$ thin film was in the metal phase, they were connected and resonated as one, showing band switching characteristics. According to the state of the $\mathrm{VO}_{2}$ thin film, the fabricated metamaterial resonated at $1.29 \mathrm{THz}$ when the two resonators were electrically separated and resonated at $0.65 \mathrm{THz}$ when the two resonators were electrically connected. In the band-switching process, the $\mathrm{THz}$ wave transmission characteristics were continuously tunable. The measurement results of the proposed structure clearly showed that the rectangular C-shaped metamaterial based on the etched $\mathrm{VO}_{2}$ thin film is capable of band switching and continuous transmission control. In the near future, band-switchable and tunable $\mathrm{THz}$ metamaterials based on etched $\mathrm{VO}_{2}$ thin films can be employed as key devices in THz wave 6G wireless communication technology.
\end{abstract}

Keywords: metamaterials; terahertz (THz); vanadium dioxide; THz-TDS; transmittance; band switching

\section{Introduction}

Terahertz (THz) technology has received considerable interest because of its potential application in various fields such as wireless communications, spectroscopy, imaging, and sensing [1-4]. Recently, many studies have been conducted on the $\mathrm{THz}$ frequency band for applications involving 6G broadband wireless communication technology [5-8]. To activate $\mathrm{THz}$ wireless communication technology, it is essential to develop various $\mathrm{THz}$ devices. Additionally, it is very important to develop a THz device capable of controlling the electromagnetic wave response characteristics for increasing the usability of the $\mathrm{THz}$ system. However, the electromagnetic properties of most natural materials are not suitable for use in the $\mathrm{THz}$ frequency band, thereby delaying the development of $\mathrm{THz}$ devices.

Metamaterials have received significant attention owing to their unique responses for manipulating electromagnetic resonances that are not normally found in natural materials [9-12]. The response of metamaterials to electromagnetic waves is determined by the structure of the metal resonator wherein the unit cell has a periodic pattern, which is smaller than the wavelength of the wave [13,14]. The resonance of metamaterials can be controlled by changing the dielectric properties of metamaterial substrates. The controllable resonance of artificially designed metamaterials can provide an opportunity to realize novel $\mathrm{THz}$ devices for various $\mathrm{THz}$ applications. Many studies have been reported 
on the implementation of tunable properties of $\mathrm{THz}$ metamaterials using semiconductors, graphene, liquid crystals, superconductors, and variable functional materials [15-20]. Vanadium dioxide $\left(\mathrm{VO}_{2}\right)$ belongs to the category of $3 \mathrm{~d} 1$ transition metal oxides, and it exhibits an insulator-metal phase transition at a critical temperature of $340 \mathrm{~K}$. The dielectric properties of the $\mathrm{VO}_{2}$ thin film-based metamaterial substrate can be controlled by the phase transition of the $\mathrm{VO}_{2}$ thin film, thereby controlling the resonance properties of the metamaterial. It is a viable candidate for the development of $\mathrm{THz}$ tunable devices because it provides superior modulation and switching characteristics in the wideband $\mathrm{THz}$ region, owing to the rapid generation characteristics of free carriers undergoing a phase transition. Tunable metamaterials based on $\mathrm{VO}_{2}$ offer a promising approach to manipulating $\mathrm{THz}$ waves due to their ease of fabrication and high tunability [21-25]. However, the $\mathrm{VO}_{2}$ thin film-based variable metamaterial is difficult to implement band-changing characteristics when the device is constructed using the entire $\mathrm{VO}_{2}$ thin film, and transmission loss is relatively large. In this study, we propose a band-switchable and tunable $\mathrm{THz}$ metamaterial based on $\mathrm{VO}_{2}$ thin films. To secure the band switching characteristics, a facing rectangular $\mathrm{C}$-shaped resonator was employed, and the $\mathrm{VO}_{2}$ thin film was etched in the form of a line

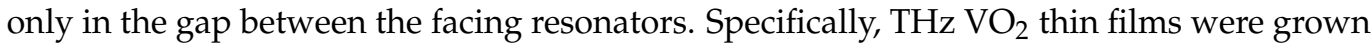
with smooth phase transition properties and high rates of change for band switching and continuously tunable metamaterial applications. The proposed etched $\mathrm{VO}_{2}$-based $\mathrm{THz}$ metamaterial exhibited a band switching characteristic while continuously changing its transmittance characteristics.

\section{Materials}

It is important to grow a vanadium dioxide $\left(\mathrm{VO}_{2}\right)$ thin film that satisfies the drastic change in electrical conductivity of more than 1000 times in the vicinity of the phase transition temperature and gradual critical temperature regime for enhancing continuous usability as a device for applications in the $\mathrm{THz}$ frequency range. Therefore, the ion-reactive RF sputtering method, which is suitable for the Volmer-Weber (VW: island formation) thin-film mode, was adopted to grow a film composed of high-quality, single-phase $\mathrm{VO}_{2}$ domains with a size of several tens of nanometers.

Specifically, $\mathrm{VO}_{2}$ thin films prepared on $\mathrm{Al}_{2} \mathrm{O}_{3}$ (0001) substrates were prepared by ion reactive radio-frequency $(\mathrm{RF})$ sputtering. During the growth process, a high-purity vanadium metal (3-inch, $>99.99 \%$ ) was employed as a sputtering target, and an RF power of $100 \mathrm{~W}$ was biased to a sputtering gun (AJA International, Inc., North Scituate, MA, USA) for $20 \mathrm{~min}$. The double-side polished $\alpha-\mathrm{Al}_{2} \mathrm{O}_{3}$ (0001) substrate temperature was maintained at $550{ }^{\circ} \mathrm{C}$, with an operating pressure of $5 \times 10^{-2}$ Torr. The $\mathrm{Ar} / \mathrm{O}_{2}$ mixed gas was maintained at a flow rate of each gas at 30 SCCM and 0.3 SCCM, respectively, within the chamber. Immediately after the sputtering process, the grown films were spontaneously cooled to room temperature.

As shown in Figure 1a, the atomic spatial arrangement of $\mathrm{VO}_{2}$ films, reconstructed onto $\mathrm{Al}_{2} \mathrm{O}_{3}(0001)$, was investigated via $\omega-2 \theta$ scan and $\phi$ scan using X-ray diffraction (XRD) (Rigaku, D/MAX-2500 diffractometer). Specifically, $\mathrm{Cu} \mathrm{K \alpha}$ radiation $(\lambda \approx 1.54 \AA$ ) was used to produce $X$-rays. Based on the sharp and symmetric diffraction peaks in XRD, a high-quality $\mathrm{VO}_{2}$ thin film was well grown on $\mathrm{Al}_{2} \mathrm{O}_{3}$, and the crystallographic epitaxial alignments were determined as $\mathrm{VO}_{2}$ [010] || $\mathrm{Al}_{2} \mathrm{O}_{3}$ [001] (out-of-plane) and $\mathrm{VO}_{2}$ [100] or $[001]$ | I $\mathrm{Al}_{2} \mathrm{O}_{3}\{110\}$ (in-plane).

To investigate the effect of electrical transport on the phase transition properties of the $\mathrm{VO}_{2}$ film, the temperature dependence of the electrical resistivity of the film was investigated using the conventional four-probe method with a heating rate of $2 \mathrm{~K} / \mathrm{min}$ in the range of $300-380 \mathrm{~K}$ under a pressure of $10^{-3}$ Torr. Figure $1 \mathrm{~b}$ shows the abrupt drop in $\Delta \rho\left(\rho_{300 \mathrm{~K}} / \rho_{370 \mathrm{k}}\right) \approx 3.6 \times 10^{3}$ in electrical resistivity near the transition temperature of $345 \mathrm{~K}$, which is defined as the apex of $\operatorname{dlog}(\rho) / \mathrm{dT}$ (inset of Figure 1b). 


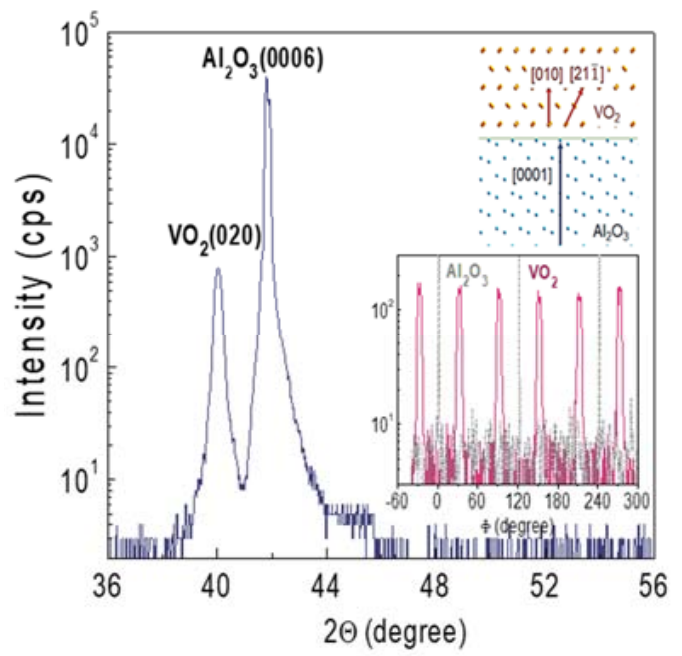

(a)

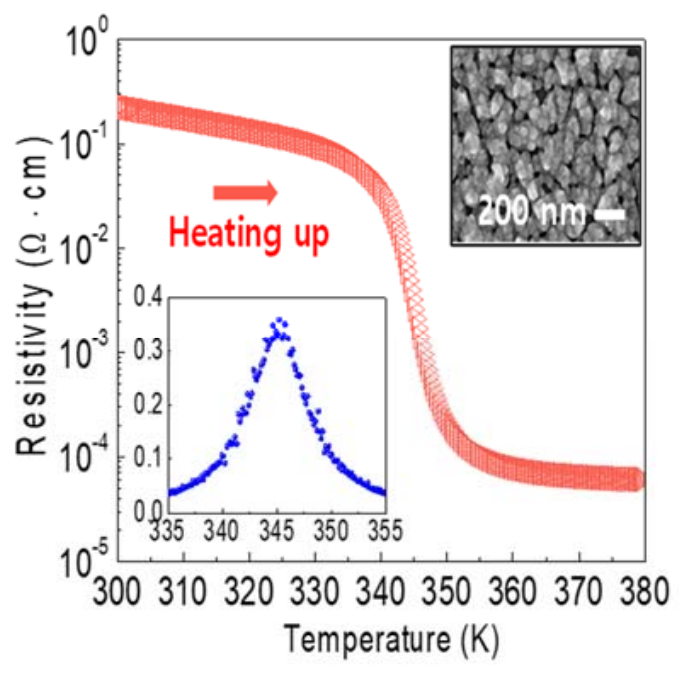

(b)

Figure 1. (a) X-ray omega-2 theta $(\omega-2 \theta)$ scan for $\mathrm{VO}_{2} / c-\mathrm{Al}_{2} \mathrm{O}_{3}$ inset (up-right: vertical crystalline alignment along the $\mathrm{VO}_{2} / \mathrm{Al}_{2} \mathrm{O}_{3}$ interface, down-right: in-plane reflection pattern of $\mathrm{VO}_{2}(011)$ peak; (b) electrical resistivity of the film as a function of temperature, inset: plain-view of SEM image (up-right), $\operatorname{dlog}(\rho) / d T$ curve in the vicinity of phase transition temperature (down-left).

\section{Design and Simulation}

To effectively control the resonance characteristics of metamaterials using the $\mathrm{VO}_{2}$ thin film, two facing rectangular C-shaped resonators were adopted for the unit cell. The $\mathrm{VO}_{2}$ thin film was etched to place the $\mathrm{VO}_{2}$ thin film only under the two gaps between the facing resonators, which significantly affected the resonant properties of the metamaterial. By etching the $\mathrm{VO}_{2}$ thin film, it is possible to control and switch the resonance band of the metamaterial by changing the conductivity of the $\mathrm{VO}_{2}$ thin film. Figure 2 shows the unit-cell structure of a band-switchable and tunable $\mathrm{THz}$ metamaterial in the form of two facing rectangular C-shaped resonators based on an etched $\mathrm{VO}_{2}$ thin film. The $\mathrm{VO}_{2}$ thin film exhibiting insulator-metal phase transition characteristics was etched in a line shape and placed in two gaps between the facing resonators. This device exhibited a structure in which two rectangular $\mathrm{C}$-shaped metal line resonators face each other and are connected to the etched line-shaped $\mathrm{VO}_{2}$ thin film. The width of the $\mathrm{VO}_{2}$ line was designed as slightly larger than the gaps between the facing resonators, to ensure a clear contact between the rectangular C-shaped metal line and $\mathrm{VO}_{2}$ thin film. When the line-shaped $\mathrm{VO}_{2}$ thin film is in the insulator phase, the two rectangular C-shaped resonators are electrically separated, thereby showing intrinsic resonance characteristics of the rectangular $\mathrm{C}$-shaped resonators. Conversely, when the $\mathrm{VO}_{2}$ thin film is in a metal phase, two resonators are electrically connected to form one resonator, and thus, new resonance characteristics are exhibited.

The unit cell of the metamaterial had a square structure, and the period length (cell_w and cell_h) was $60 \mu \mathrm{m}$. The vertical length (L) of the rectangular C-shaped resonator was $50 \mu \mathrm{m}$, and the horizontal length of the two rectangular C-shaped resonators connected with the width of the etched $\mathrm{VO}_{2}$ thin film line was $50 \mu \mathrm{m}$, which was the same as the vertical length. For stable contact between the resonators and thin film, the gap of the rectangular C-shaped resonator was set to $5 \mu \mathrm{m}$, and the width of the $\mathrm{VO}_{2}$ thin film line was set to $10 \mu \mathrm{m}$. To easily implement with general photolithography technology, the width of the metal line forming the metamaterial was set to $5 \mu \mathrm{m}$. The proposed metamaterial exhibits different transmission characteristics based on the polarization state of the incident $\mathrm{THz}$ electric field. As shown in Figure 2, mode 1 implies that the polarization of the electric field is parallel to the etched $\mathrm{VO}_{2}$ thin film line, and mode 2 implies that the polarization is perpendicular to the line. The proposed THz metamaterial was simulated using ANSYS HFSS electromagnetic wave simulator. The dielectric properties of the $\mathrm{VO}_{2}$ thin film are 
dependent on the change in the conductivity of the thin film, and the conductivity of the $\mathrm{VO}_{2}$ thin film changes with temperature. To simulate the change in the $\mathrm{THz}$ electromagnetic properties of the band-switchable and tunable metamaterial composed of the etched $\mathrm{VO}_{2}$ thin film, the change in $\mathrm{VO}_{2}$ conductivity based on the temperature was set in the range of $100-1,000,000 \mathrm{~S} / \mathrm{m}$. Additionally, the permittivity and dielectric loss tangent of the $\mathrm{VO}_{2}$ thin film were fixed to 9.1 and 0 , respectively, and the frequency dependence of the material was not considered. Table 1 shows the detailed material constants used in the simulation.

\section{E-Field \\ Polarization Mode 1 Mode 2}

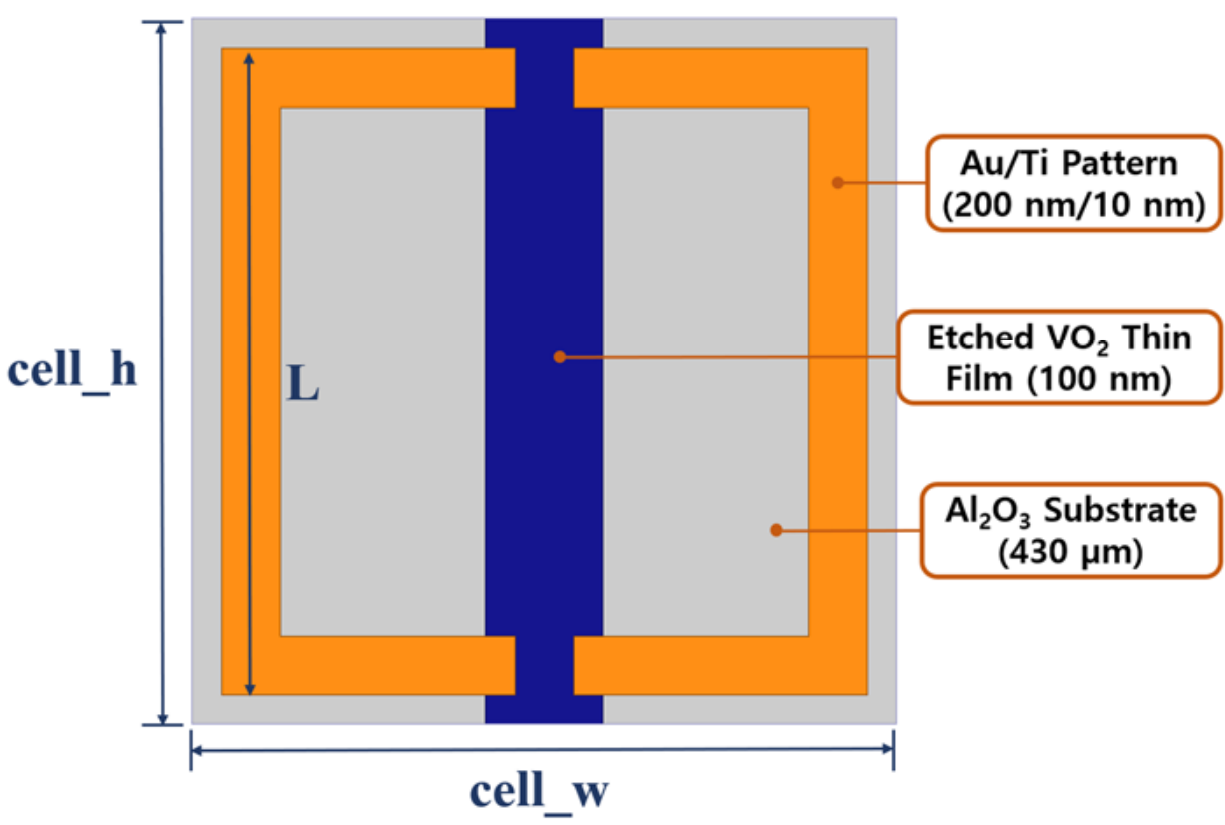

Figure 2. Schematic diagram of a band-switchable and tunable $\mathrm{THz}$ metamaterial in the form of two facing rectangular $\mathrm{C}$-shaped resonators based on an etched $\mathrm{VO}_{2}$ thin film.

Table 1. Properties of the $\mathrm{VO}_{2}$ and Alumina used in the simulation.

\begin{tabular}{ccc}
\hline Parameter & Vanadium Dioxide $\left(\mathbf{V O}_{\mathbf{2}}\right)$ & $\begin{array}{c}\text { Alumina } \\
\left(\mathbf{A l}_{\mathbf{2}} \mathbf{O}_{\mathbf{3}}\right)\end{array}$ \\
\hline Relative permittivity & 9.1 & 9.4 \\
Dielectric loss tangent & 0 & 0.001 \\
Conductivity (simens $/ \mathrm{m})$ & $100-1,000,000$ & 0 \\
\hline
\end{tabular}

The transmittance levels of the proposed metamaterial operating in modes 1 and 2 are shown in Figure 3. In the case of mode 1, resonance occurs predominantly due to the vertical structure length of the two facing rectangular C-shaped resonator structures because the direction of the incident $\mathrm{THz}$ electric field is the same as the direction of the etched $\mathrm{VO}_{2}$ thin film line pattern. This resonance appears in the $0.7 \mathrm{THz}$ band, as shown in Figure $3 \mathrm{a}$. As the conductivity of the $\mathrm{VO}_{2}$ thin film increases, the quality factor ( $Q$ factor) of the $\mathrm{THz}$ metamaterial decreases, and the resonance strength of the metamaterial is weakened. When the conductivity of the $\mathrm{VO}_{2}$ thin film exceeds $50,000 \mathrm{~S} / \mathrm{m}$, and the $\mathrm{VO}_{2}$ thin film changes from an insulator to a metallic phase, the overall transmittance characteristics of the metamaterial deteriorate. Additionally, the resonance at low frequencies is strengthened by the long length of the metallic $\mathrm{VO}_{2}$ line. 


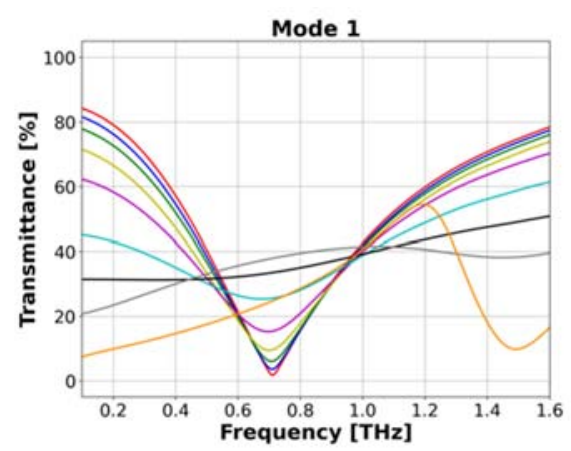

(a)

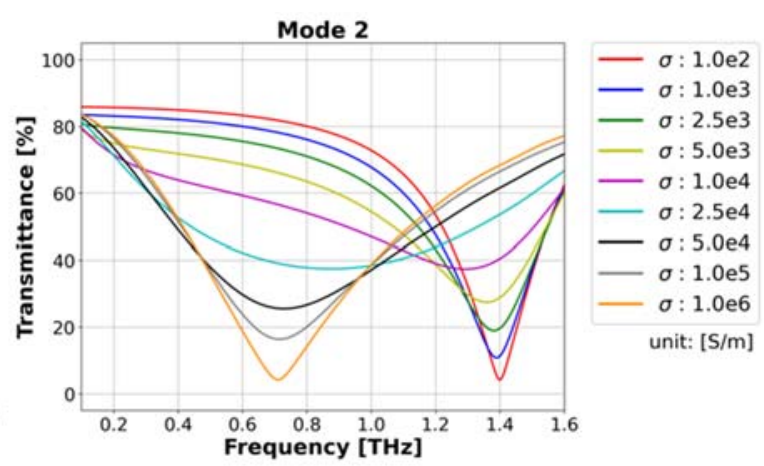

(b)

Figure 3. Transmittances of a band-switchable and tunable $\mathrm{THz}$ metamaterial in the form of two facing rectangular $\mathrm{C}$-shaped resonators based on an etched $\mathrm{VO}_{2}$ thin film operating in (a) mode 1 and (b) mode 2 .

As shown in Figure 3b, in the case of mode 2, the direction of the incident $\mathrm{THz}$ electric field is perpendicular to the direction of the etched $\mathrm{VO}_{2}$ thin film line pattern, thereby leading to fundamental resonance in the horizontal structure of the $\mathrm{C}$-shaped resonator. Therefore, when the $\mathrm{VO}_{2}$ thin film is in the insulator phase, the fundamental resonance of mode 2 occurs in the $1.4 \mathrm{THz}$ band, which is approximately twice the frequency band of the fundamental resonance of mode 1 . This is because the metamaterial of the two rectangular $\mathrm{C}$-shaped resonators facing each other with the etched $\mathrm{VO}_{2}$ thin film exhibit a square structure. Hence, the resonance due to the vertical-versus-horizontal structure of the rectangular C-shaped resonator leads to a double frequency difference. During the phase transition of the $\mathrm{VO}_{2}$ film from insulator to metal, the quality factor and resonance strength of $\mathrm{THz}$ metamaterials gradually decrease as the conductivity of the $\mathrm{VO}_{2}$ film increases from $100 \mathrm{~S} / \mathrm{m}$ to $25,000 \mathrm{~S} / \mathrm{m}$. As the conductivity of the $\mathrm{VO}_{2}$ thin film increases to more than $25,000 \mathrm{~S} / \mathrm{m}$, the quality factor and resonance strength of metamaterials gradually increase again, and the $1.4 \mathrm{THz}$ fundamental resonance is switched to a new $0.7 \mathrm{THz}$ resonance. The $\mathrm{VO}_{2}$ thin film in the metal phase electrically connects the two rectangular C-shaped resonators via the phase transition of the $\mathrm{VO}_{2}$ thin film, thereby resulting in a resonance similar to the resonance due to the vertical structure of the $\mathrm{C}$-shaped resonator generated in mode 1. It can be confirmed that the resonance of the proposed metamaterial can be gradually tuned, and the resonance band can be switched via the insulator-metal phase transition of the $\mathrm{VO}_{2}$ thin film. In the process of changing the $\mathrm{VO}_{2}$ thin film from an insulator phase to a metal phase, the transmittance of the metamaterial changed from $82.5 \%$ to $4.0 \%$ in the $0.7 \mathrm{THz}$ band, and from $3.7 \%$ to $69.5 \%$ in the $1.4 \mathrm{THz}$ band.

Figure 4 shows the surface current density of the proposed metamaterial operating in mode 2. Figure $4 \mathrm{a}, \mathrm{b}$ show the surface current density induced in the metamaterial at a resonance frequency of $1.4 \mathrm{THz}$, when the $\mathrm{VO}_{2}$ thin film is in the insulator phase, and $0.71 \mathrm{THz}$, when the thin film is in the metal phase, respectively. Figure 4a shows that each resonance generated in the two rectangular C-shaped resonators is clearly separated owing to the insulating properties of the $\mathrm{VO}_{2}$ thin film. Conversely, in the case of Figure $4 \mathrm{~b}$, two rectangular $\mathrm{C}$-shaped resonators and the $\mathrm{VO}_{2}$ thin film are electrically connected to form a resonance similar to that of a single resonator due to the metallic properties of the $\mathrm{VO}_{2}$ thin film.

The variation in the transmittance of the proposed metamaterial in two resonance states according to the phase transition of the $\mathrm{VO}_{2}$ thin film is shown in Figure 5. The blue line shows the change in transmittance at a resonance frequency of $1.4 \mathrm{THz}$ when $\mathrm{VO}_{2}$ is in the insulator phase, and the red line shows the change in transmittance at the resonance frequency of $0.71 \mathrm{THz}$ in the case of the metal phase. The rate of change in transmittance of the metamaterial at the resonance frequency was $65.8 \%$ and $78.5 \%$ when the $\mathrm{VO}_{2}$ thin film was in the insulator phase and metal phase, respectively. It was confirmed 
that the proposed metamaterial using the etched $\mathrm{VO}_{2}$ thin film exhibits high tunability of transmittance and band switching characteristics.

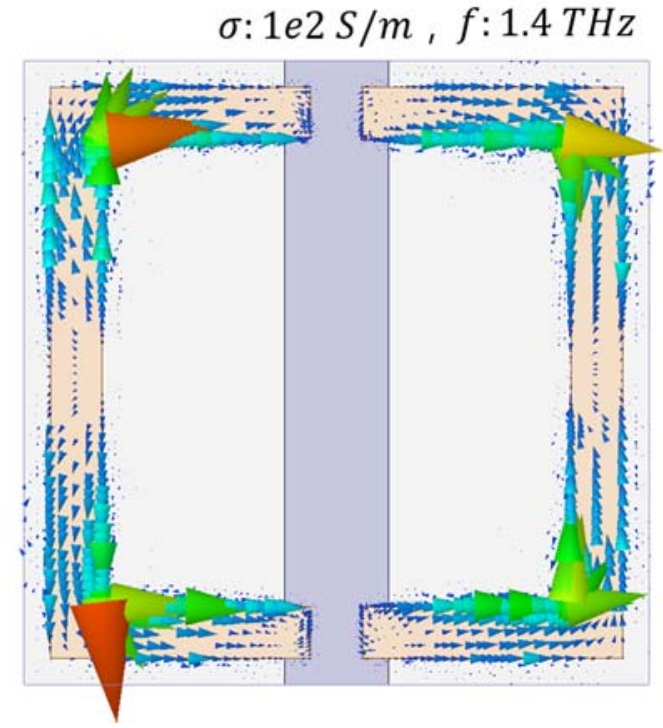

(a)

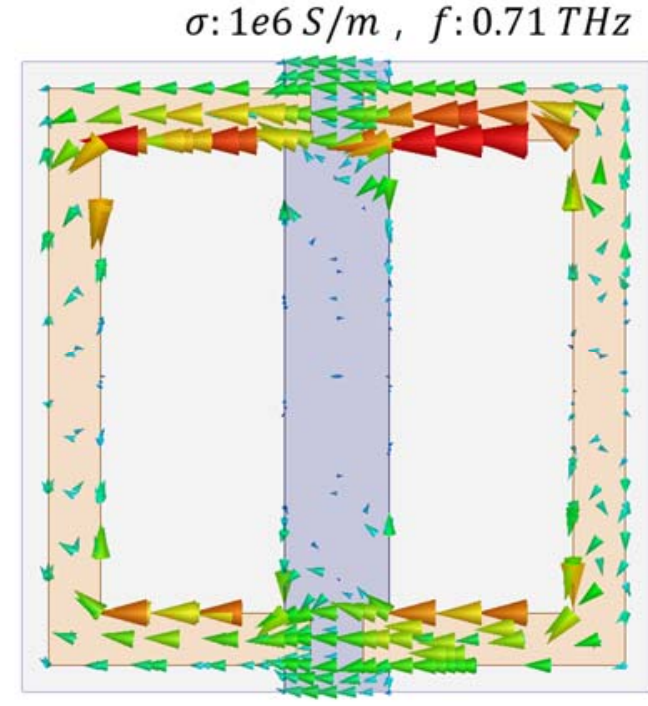

(b)

Figure 4. Surface current density of a band-switchable and tunable $\mathrm{THz}$ metamaterial in the form of two-facing rectangular $\mathrm{C}$-shaped resonators based on an etched $\mathrm{VO}_{2}$ thin film operating in mode 2 : (a) insulator phase $(\sigma=100 \mathrm{~S} / \mathrm{m}, \mathrm{f}=1.4 \mathrm{THz})$ and $(\mathbf{b})$ metal phase $(\sigma=100 \mathrm{~S} / \mathrm{m}, \mathrm{f}=1.4 \mathrm{THz})$.

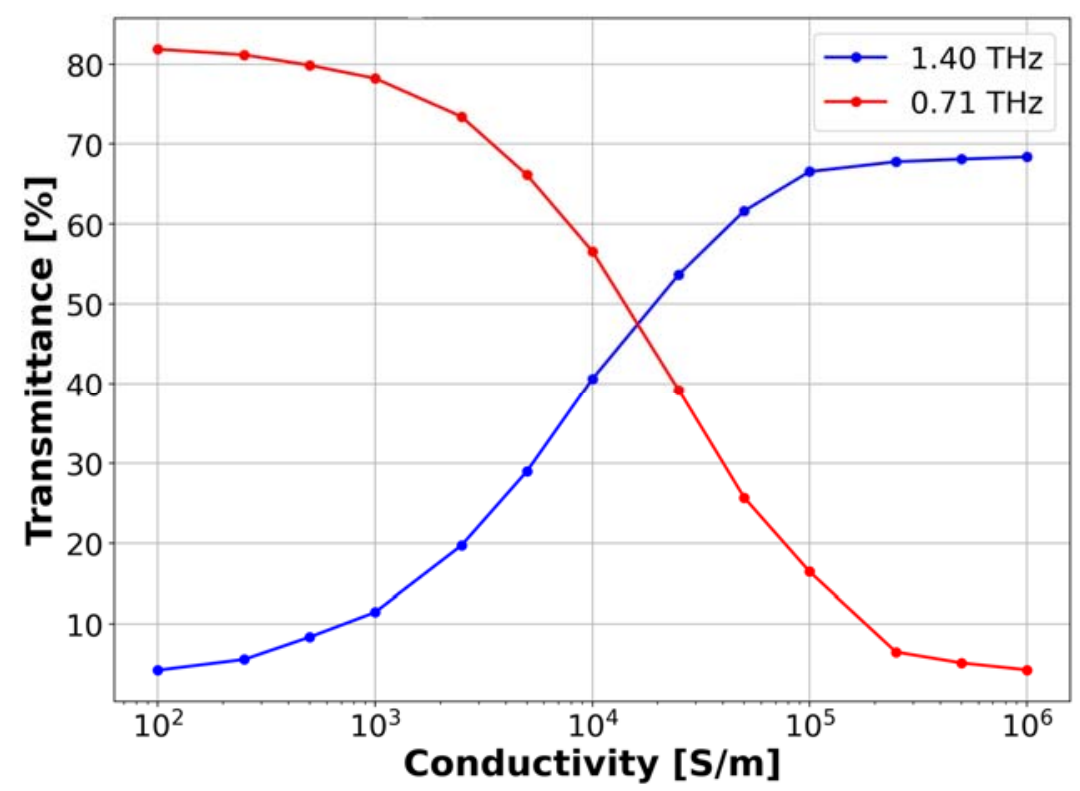

Figure 5. Variation in transmittance of the proposed metamaterial in two resonance states (blue line: insulator phase and $\mathrm{f}=1.4 \mathrm{THz}$; red line: metal phase and $\mathrm{f}=0.71 \mathrm{THz}$ ) based on the phase transition of the $\mathrm{VO}_{2}$ thin film.

\section{Measurement and Discussions}

As a substrate for $\mathrm{VO}_{2}$ thin film deposition, alumina $\left(\mathrm{Al}_{2} \mathrm{O}_{3}\right)$ with a thickness of $430 \mu \mathrm{m}$ was used. Alumina exhibits a similar dielectric constant as that of $\mathrm{VO}_{2}$ in an insulator phase, and it is widely used as a substrate for $\mathrm{VO}_{2}$ deposition. The thickness of $\mathrm{VO}_{2}$ was set as $100 \mathrm{~nm}$. The temperature dependence of the electrical conductivity of the $\mathrm{VO}_{2}$ thin film was measured in the in-plane direction using a 4-probe measurement. The measured conductivity was 100 and close to $1,000,000 \mathrm{~S} / \mathrm{m}$ in insulator and metal phases, 
respectively. The deposited $\mathrm{VO}_{2}$ thin film was etched using a reactive ion etching method to induce variability and band switching characteristics to the resonance characteristics of the proposed metamaterial. The etching of $\mathrm{VO}_{2}$ was performed for 3 min under standard etching conditions with an RF power of $200 \mathrm{~W}$ in gas mixtures based on $\mathrm{CF}_{4}$ and $\mathrm{O}_{2}$ at an operating pressure of 50 mTorr. To prove that the proposed metamaterial can exhibit tunability and band-switching functions, two rectangular C-shaped resonators were fabricated facing each other on an etched $\mathrm{VO}_{2}$ thin film line. A gold electrode $(200 \mathrm{~nm})$ with a Ti adhesive layer $(20 \mathrm{~nm})$ was deposited on the etched $\mathrm{VO}_{2}$ thin film via the DC sputtering method. The designed metamaterial was patterned using general photolithography and a lift-off process. Figure 6 shows a photograph of the fabricated band-switchable and tunable $\mathrm{THz}$ metamaterial in the form of two rectangular $\mathrm{C}$-shaped resonators facing each other on an etched $\mathrm{VO}_{2}$ thin film.

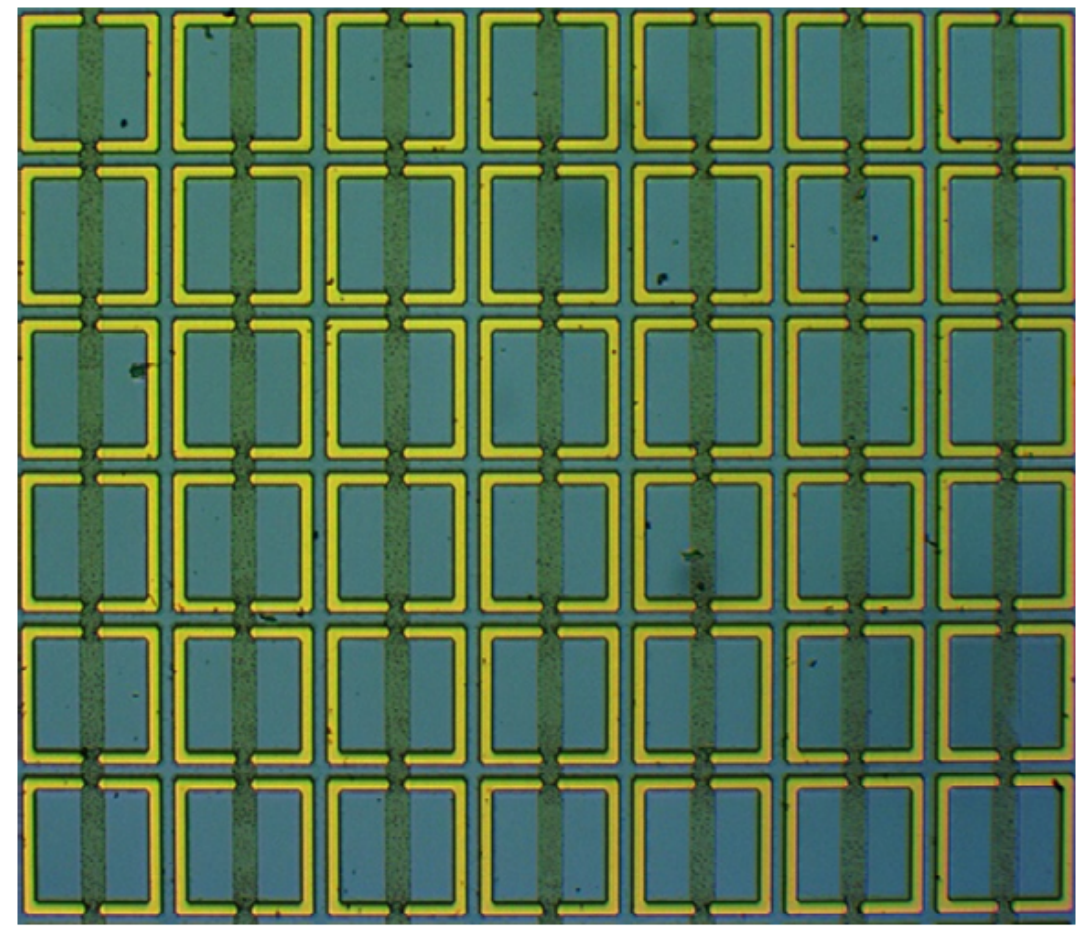

Figure 6. Photograph of the band-switchable and tunable $\mathrm{THz}$ metamaterial in the form of two rectangular $\mathrm{C}$-shaped resonators facing each other on an etched $\mathrm{VO}_{2}$ thin film.

The designed and fabricated metamaterials were measured using a $\mathrm{THz}$ time-domain spectroscopy (THz-TDS) system with an operating frequency range of 0.1 to $4 \mathrm{THz}$ and a dynamic range greater than $60 \mathrm{~dB}$ at peak frequencies. (ADVANTEST TAS7400). To measure band switching and tunable characteristics based on the change in conductivity of the $\mathrm{VO}_{2}$ thin film, the fabricated material was placed on an external heater, with a hole in the center such that the $\mathrm{THz}$ wave can be appropriately transmitted. The voltage applied to the external heater can control the temperature of the heater, which, in turn, controls the conductivity of the $\mathrm{VO}_{2}$ thin film. Figure $7 \mathrm{a}, \mathrm{b}$ show the $\mathrm{THz}$ time-domain waveforms of the metamaterials with respect to the voltage applied to the heater in modes 1 and 2, respectively. The measurement of the transmission characteristics was varied based on the polarization of the incident $\mathrm{THz}$ wave. When the polarization of the incident light was perpendicular to the $\mathrm{VO}_{2}$ thin film, the transmittance of the $\mathrm{THz}$ wave was higher than when it was parallel. Hence, the $\mathrm{THz}$ wave passing through the metamaterial was larger in mode 2 than in mode 1. Additionally, as the applied voltage increased and conductivity of the $\mathrm{VO}_{2}$ thin film increased, the transmission of $\mathrm{THz}$ waves generally decreased. 


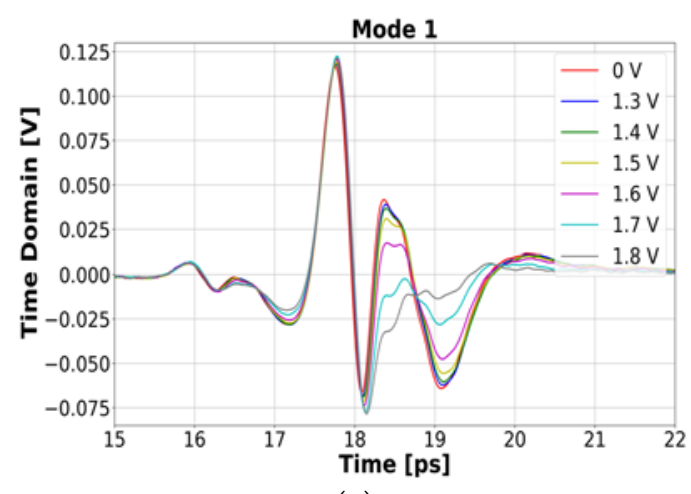

(a)

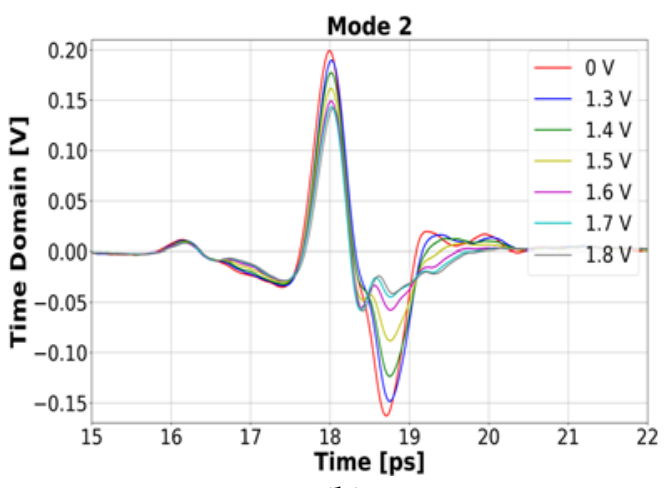

(b)

Figure 7. THz time-domain waveforms of metamaterials with respect to the applied voltage: (a) mode 1 and (b) mode 2 .

Figure $8 \mathrm{a}, \mathrm{b}$ show the transmittances of the metamaterials according to the voltage applied to the heater in modes 1 and 2, respectively. The transmittance gradually changed in both modes based on the applied voltage. When the $\mathrm{VO}_{2}$ thin film is in an insulator phase, the metamaterial operating in mode 2 resonates at $1.29 \mathrm{THz}$, which is approximately twice the resonant frequency of the metamaterial operating in mode 1 at $0.65 \mathrm{THz}$. Although the resonant frequency of the fabricated metamaterial is slightly lower than the resonant frequency of the simulation shown in Figure 3, the measurement results indicate the same overall trend as the simulation results. In mode 2, the proposed metamaterial exhibited band-switchable and tunable transmission characteristics. As the applied voltage increased from $0 \mathrm{~V}$ to $1.5 \mathrm{~V}$, the resonant frequency of the metamaterial decreased and Q-factor gradually decreased. When the applied voltage exceeded $1.6 \mathrm{~V}$, and the $\mathrm{VO}_{2}$ thin film approached the metal phase, the resonance of the metamaterial gradually switched to the $0.65 \mathrm{THz}$ band, and the $\mathrm{Q}$-factor increased again. The maximum resonance strength measured in the $0.65 \mathrm{THz}$ band of Figure $8 \mathrm{~b}$ is weaker than the simulation result of Figure $3 \mathrm{~b}$. Figures $3 \mathrm{~b}$ and $8 \mathrm{~b}$ show that the maximum conductivity of the $\mathrm{VO}_{2}$ thin film when measured is approximately $2 \mathrm{e} 5 \mathrm{~S} / \mathrm{m}$, which is lower than the maximum conductivity of $1 \mathrm{e} 6 \mathrm{~S} / \mathrm{m}$ used in the simulation. Although the maximum value of the conductivity of the $\mathrm{VO}_{2}$ thin film does not reach the value used in the simulation, it was similar to the generally reported maximum value. Hence, it can be confirmed that the deposited $\mathrm{VO}_{2}$ thin film exhibits a high rate of change in conductivity while it continuously changes. In order to more accurately match the simulation results with the measurement results, the exact dielectric properties of the alumina and $\mathrm{VO}_{2}$ thin films measured in the terahertz band with frequency dependence should be applied to the simulation.

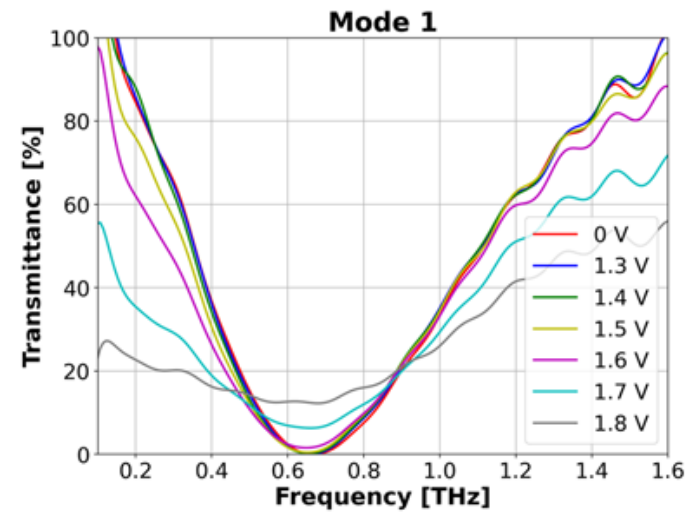

(a)

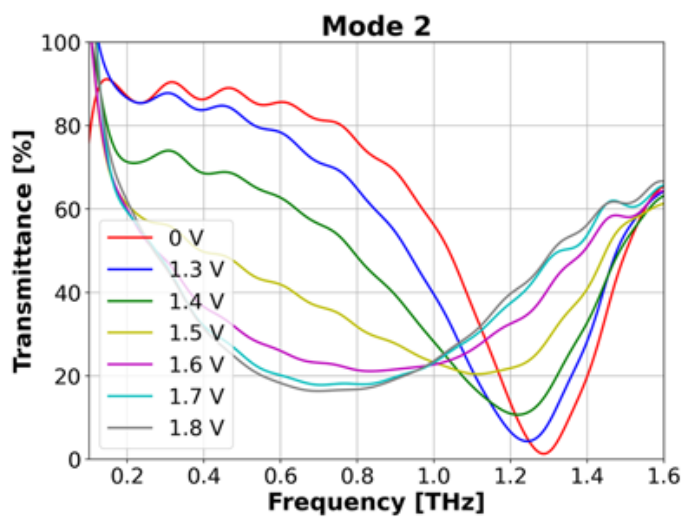

(b)

Figure 8. THz transmittance of metamaterials according to the applied voltage change (a) mode 1 and (b) mode 2 . 
The band-switchable and tunable properties of $\mathrm{THz}$ metamaterials were successfully implemented using a rectangular C-shaped metal resonator and an etched $\mathrm{VO}_{2}$ thin film. The resonant frequency of the fabricated metamaterial was lower than the simulation result. However, this can be easily adjusted by reducing the overall size of the metamaterial structure. The resonance strength of metamaterials was weaker when $\mathrm{VO}_{2}$ was in a metal phase than when it was in an insulator phase. This can be solved by improving the properties of the $\mathrm{VO}_{2}$ thin film. Our measurement results clearly showed that the rectangular $\mathrm{C}$-shaped metamaterial based on the etched $\mathrm{VO}_{2}$ thin film is capable of band switching and continuous transmittance control. As a result of evaluating the switching speed of the device for terahertz waves, the switching cycle time (insulating phase $\rightarrow$ metal phase $\rightarrow$ insulating phase) was measured to be $0.614 \mathrm{~s}$. In the future, it is possible to improve the switching speed by controlling the strain at the interface between the thin film and the substrate, the type of dopant, and the doping concentration.

In this study, a novel structure in which a $\mathrm{VO}_{2}$ thin film is etched and combined with a metal structure was proposed to realize continuous terahertz band switching characteristics. The use of high-quality etched $\mathrm{VO}_{2}$ thin films with various types of metal resonators is expected to enable novel THz-tunable devices. The development of these tunable $\mathrm{THz}$ devices can aid in accelerating the commercialization of THz-wave 6G wireless communication technology.

\section{Conclusions}

We proposed a band-switchable and tunable THz metamaterial based on an etched vanadium dioxide $\left(\mathrm{VO}_{2}\right)$ thin film. To secure the band-switchable characteristics of the metamaterial, the $\mathrm{VO}_{2}$ thin film was etched and patterned in the form of a line. The metamaterial consisted of two rectangular C-shaped resonators facing each other, and a $\mathrm{VO}_{2}$ thin film line was formed between the resonator gaps. Therefore, the operating band of the metamaterial can be switched by controlling the state of the $\mathrm{VO}_{2}$ thin film because the two C-shaped resonators are electrically separated when the $\mathrm{VO}_{2}$ thin film is in the insulator phase and electrically connected when the $\mathrm{VO}_{2}$ thin film is in the metal phase. Additionally, it was possible to continuously control the $\mathrm{THz}$ wave transmittance of the metamaterial by growing the $\mathrm{VO}_{2}$ thin film such that smooth phase transition can be realized, as opposed to rapid transition. As the phase transition of the $\mathrm{VO}_{2}$ thin film occurred, the resonance band of the metamaterial shifted from the $1.29 \mathrm{THz}$ band to the $0.65 \mathrm{THz}$ band. During the band-switching process, the resonant strength of the metamaterial can be tuned continuously. The proposed metamaterial based on the etched $\mathrm{VO}_{2}$ thin film successfully exhibits band-switching and tunable characteristics, and it is expected to be usefully applied to $\mathrm{THz}$ wave $6 \mathrm{G}$ wireless communication technology.

Author Contributions: Conceptualization, J.-H.S. and K.H.P.; methodology, J.-H.S., K.H.P. and H.C.R.; software, H.-C.R.; writing-original draft preparation, J.-H.S. and H.-C.R.; writing-review and editing, H.-C.R.; supervision, H.-C.R. All authors have read and agreed to the published version of the manuscript.

Funding: This study was supported by the Fund of Sahmyook University in 2020.

Institutional Review Board Statement: Not applicable.

Informed Consent Statement: Not applicable.

Data Availability Statement: Data are contained within the article.

Conflicts of Interest: The authors declare that they have no known competing financial interests or personal relationships that could have influenced the research reported in this paper.

\section{References}

1. Tonouchi, M. Cutting-edge terahertz technology. Nat. Photonics 2007, 1, 97-105. [CrossRef]

2. Jepsen, P.U.; Cooke, D.G.; Koch, M. Terahertz spectroscopy and imaging-Modern techniques and applications. Laser Photonics Rev. 2011, 5, 124. [CrossRef] 
3. Zhang, X.C.; Shkurinov, A.; Zhang, Y. Extreme terahertz science. Nat. Photonics 2017, 11, 16-18. [CrossRef]

4. Liu, H.B.; Zhong, H.; Karpowicz, N.; Chen, Y.; Zhang, X.C. Terahertz spectroscopy and imaging for defense and security applications. Proc. IEEE 2007, 95, 1514-1527. [CrossRef]

5. Huang, K.-C.; Wang, Z. Terahertz terabit wireless communication. IEEE Microw. Mag. 2011, 12, 108-116. [CrossRef]

6. Yang, Y.; Yamagami, Y.; Yu, X.; Pitchappa, P.; Webber, J.; Zhang, B.; Fujita, M.; Nagatsuma, T.; Singh, R. Terahertz topological photonics for on-chip communication. Nat. Photonics 2020, 14, 446-451. [CrossRef]

7. Dan, I.; Ducournau, G.; Hisatake, S.; Szriftgiser, P.; Braun, R.; Kallfass, I. A terahertz wireless communication link using a superheterodyne approach. IEEE Trans. Terahertz Sci. Technol. 2020, 10, 2-43. [CrossRef]

8. Ryu, H.-C.; Kim, N.; Han, S.-P.; Ko, H.; Park, J.-W.; Moon, K.; Park, K.H. Simple and cost-effective thickness measurement terahertz system based on a compact $1.55 \mu \mathrm{m} \lambda / 4$ phase-shifted dual-mode laser. Opt. Express 2012, 20, 25990-25999. [CrossRef] [PubMed]

9. Valentine, J.; Zhang, S.; Zentgraf, T.; Ulin-Avila, E.; Genov, D.A.; Bartal, G.; Zhang, X. Three-dimensional optical metamaterial with negative refractive index. Nature 2008, 455, 376-379. [CrossRef] [PubMed]

10. Schurig, D.; Mock, J.J.; Justice, B.J.; Cummer, S.A.; Pendry, J.B.; Starr, A.F.; Smith, D.R. Metamaterial electromagnetic cloak at microwave frequencies. Science 2006, 314, 977-979. [CrossRef]

11. Poddubny, A.; Iorsh, I.; Belov, P.; Kivshar, Y. Hyper metamaterials. Nat. Photonics 2013, 28, $958-967$.

12. Huo, P.; Zhang, S.; Liang, Y.; Lu, Y.; Xu, T. Hyperbolic metamatrials and metasurfaces: Fundamentals and applications. Adv. Opt. Mater. 2019, 7, 1801616. [CrossRef]

13. Choi, M.; Lee, S.H.; Kim, Y.; Kang, S.B.; Shin, J.; Kwak, M.H.; Kang, K.-Y.; Lee, Y.-H.; Park, N.; Min, B. A terahertz metamaterial with unnaturally high refractive index. Nature 2011, 470, 369-373. [CrossRef]

14. Chen, H.-T.; Padilla, W.J.; Zide, J.M.O.; Gossard, A.C.; Taylor, A.J.; Averitt, R.D. Active terahertz metamaterial devices. Nature 2006, 444, 597-600. [CrossRef] [PubMed]

15. Chen, H.-T.; Padilla, W.J.; Cich, M.J.; Azad, A.K.; Averitt, R.D. A metamaterial solid-state terahertz phase modulator. Nat. Photonics 2009, 22, 148-151. [CrossRef]

16. Ju, L.; Geng, B.; Horng, J.; Girit, C.; Martin, M.; Hao, Z.; Bechtel, H.A.; Liang, X.; Zettl, A.; Shen, Y.R.; et al. Graphene plasmonics for tunable terahertz metamaterials. Nat. Nanotechnol. 2011, 4, 630-634. [CrossRef] [PubMed]

17. Sensale-Rodriguez, B.; Yan, R.; Kelly, M.M.; Fang, T.; Tahy, K.; Hwang, W.S.; Jena, D.; Liu, L.; Xing, H.G. Broadband graphene terahertz modulators enabled by intraband transition. Nat. Commun. 2012, 3, 1-7. [CrossRef] [PubMed]

18. Kowerdziej, R.; Jaroszewicz, L. Active control of terahertz radiation using a metamaterial loaded with a nematic liquid crystal. Liq. Cryst. 2016, 43, 1120-1125. [CrossRef]

19. Vafapour, Z.; Dutta, M.; Stroscio, M.A. Sensing, switching and modulating applications of a superconducting THz metamaterial IEEE Sens. J. 2021, 21, 15187-15195. [CrossRef]

20. Cao, Y.; Gan, S.; Geng, Z.; Liu, J.; Yang, Y.; Bao, Q.; Chen, H. Optically tuned terahertz modulator based on annealed multilayer $\mathrm{MoS}_{2}$. Sci. Rep. 2016, 6, 22899. [CrossRef] [PubMed]

21. Wen, Q.-Y.; Zhang, H.-W.; Yang, Q.-H.; Xie, Y.-S.; Chen, K.; Liu, Y.-L. Terahertz metamaterials with $\mathrm{VO}_{2}$ cut-wires for thermal tenability. Appl. Phys. Lett. 2010, 97, 021111. [CrossRef]

22. Liu, M.; Hwang, H.Y.; Tao, H.; Strikwerda, A.C.; Fan, K.; Keiser, G.R.; Sternbach, A.J.; West, K.G.; Kittiwatanakul, S.; Lu, J.; et al. Terahertz-field-induced insulator-to-metal transition in vanadium dioxide metamaterial. Nature 2012, 487, 345-348. [CrossRef] [PubMed]

23. Shin, J.H.; Park, K.H.; Ryu, H.C. Electrically controllable terahertz square-loop metamaterial based on $\mathrm{VO}_{2}$ thin film Nanotechnology 2016, 27, 195202. [CrossRef] [PubMed]

24. Park, D.J.; Shin, J.H.; Park, K.H.; Ryu, H.C. Electrically controllable THz asymmetric split-loop resonator with an outer square loop based on $\mathrm{VO}_{2}$. Opt. Express 2018, 26, 17397-17406. [CrossRef] [PubMed]

25. Shin, J.H.; Han, S.P.; Song, M.; Ryu, H.C. Gradual tuning of the terahertz passband using a square-loop metamaterial based on a W-doped $\mathrm{VO}_{2}$ thin film. Appl. Phys. Express 2019, 12, 032007. [CrossRef] 